\title{
The Uncommon Active Site of D-Amino Acid Transaminase from Haliscomenobacter hydrossis: Biochemical and Structural Insights into the New Enzyme
}

\author{
Alina K. Bakunova ${ }^{1}$, Alena Yu. Nikolaeva ${ }^{1}$, Tatiana V. Rakitina ${ }^{1,2}$, Tatiana Y. Isaikina ${ }^{1}$, Maria G. Khrenova ${ }^{1,3}{ }^{\mathbb{D}}$, \\ Konstantin M. Boyko ${ }^{1}\left(\mathbb{D}\right.$, Vladimir O. Popov ${ }^{1}$ and Ekaterina Yu. Bezsudnova ${ }^{1, *(\mathbb{D})}$ \\ 1 Bach Institute of Biochemistry, Research Center of Biotechnology of the Russian Academy of Sciences, \\ Leninsky Ave. 33, bld. 2, 119071 Moscow, Russia; a.bakunova@fbras.ru (A.K.B.); aishome@mail.ru (A.Y.N.); \\ taniarakitina@yahoo.com (T.V.R.); inbimaldi@gmail.com (T.Y.I.); mkhrenova@lcc.chem.msu.ru (M.G.K.); \\ boiko_konstantin@inbi.ras.ru (K.M.B.); vpopov@inbi.ras.ru (V.O.P.) \\ 2 Shemyakin \& Ovchinnikov Institute of Bioorganic Chemistry of the Russian Academy of Sciences, \\ Miklukho-Maklaya Str. 16/10, 117997 Moscow, Russia \\ 3 Chemistry Department, Lomonosov Moscow State University, Leninskiye Gory 1/3, 119991 Moscow, Russia \\ * Correspondence: author eubez@inbi.ras.ru
}

Citation: Bakunova, A.K.; Nikolaeva, A.Y.; Rakitina, T.V.; Isaikina, T.Y.; Khrenova, M.G.; Boyko, K.M.; Popov, V.O.; Bezsudnova, E.Y. The Uncommon Active Site of D-Amino Acid Transaminase from Haliscomenobacter hydrossis: Biochemical and Structural Insights into the New Enzyme. Molecules 2021, 26, 5053. https:// doi.org/10.3390/molecules26165053

Academic Editor: Marko Goliĉnik

Received: 23 July 2021

Accepted: 17 August 2021

Published: 20 August 2021

Publisher's Note: MDPI stays neutral with regard to jurisdictional claims in published maps and institutional affiliations.

Copyright: (c) 2021 by the authors. Licensee MDPI, Basel, Switzerland. This article is an open access article distributed under the terms and conditions of the Creative Commons Attribution (CC BY) license (https:// creativecommons.org/licenses/by/ $4.0 /)$.
Abstract: Among industrially important pyridoxal-5'-phosphate (PLP)-dependent transaminases of fold type IV D-amino acid transaminases are the least studied. However, the development of cascade enzymatic processes, including the synthesis of D-amino acids, renewed interest in their study. Here, we describe the identification, biochemical and structural characterization of a new D-amino acid transaminase from Haliscomenobacter hydrossis (Halhy). The new enzyme is strictly specific towards D-amino acids and their keto analogs; it demonstrates one of the highest rates of transamination between D-glutamate and pyruvate. We obtained the crystal structure of the Halhy in the holo form with the protonated Schiff base formed by the K143 and the PLP. Structural analysis revealed a novel set of the active site residues that differ from the key residues forming the active sites of the previously studied D-amino acids transaminases. The active site of Halhy includes three arginine residues, one of which is unique among studied transaminases. We identified critical residues for the Halhy catalytic activity and suggested functions of the arginine residues based on the comparative structural analysis, mutagenesis, and molecular modeling simulations. We suggested a strong positive charge in the O-pocket and the unshaped P-pocket as a structural code for the D-amino acid specificity among transaminases of PLP fold type IV. Characteristics of Halhy complement our knowledge of the structural basis of substrate specificity of D-amino acid transaminases and the sequence-structure-function relationships in these enzymes.

Keywords: D-amino acid transaminase; enzyme catalysis; substrate specificity; X-ray analysis; arginine residues; sequence-structure-function relationships

\section{Introduction}

The superfamily of pyridoxal-5'-phosphate (PLP)-dependent transaminases (TAs; aminotransferases; EC 2.6.1.) is an excellent basis for studying sequence-structure-function relationships in enzymes: TAs exhibit a diversity of substrate specificity and activity using a uniform structural scaffold. TAs catalyze the stereoselective transfer of an amino group from an amino acid/amine to a keto acid/ketone/aldehyde, producing a new chiral amino acid/amine and a new keto compound. The transamination reaction proceeds via a double displacement reversible mechanism; one catalytic turnover includes two half-reactions with the conversion of covalently bound cofactor PLP to free pyridoxamine 5'-phosphate (PMP) and release of the first product and subsequent recovery of the PLP form of cofactor accompanying by transfer of the amino group to a keto substrate and the release of a new amino compound [1-3]. 
Transaminases belong to fold types I and IV of the PLP-dependent enzymes. The superfamily of PLP-dependent TAs of fold IV (a superfamily of D-amino acid aminotransferases) includes three canonical families: D-amino acid TAs (DAATs, EC 2.6.1.21), branched-chain L-amino acid TAs (BCATs, EC 2.6.1.42), and (R)-amine:pyruvate TAs (R-TAs, EC 2.6.1.X). Strict $(R)$-selectivity or (S)-selectivity of TAs of PLP fold type IV is implemented within geometrically similar active sites and results from the different amino acid compositions. Transaminases are usually homodimers, comprising two symmetrical active sites formed by the residues of both subunits. Characteristics of the residues in the active site determine the substrate specificity of TAs. Two specificity-determining sequence motifs, comprising residues of the active site, were identified to distinguish the substrate preferences of canonical TAs of PLP fold type IV [4-6]. Recently, TAs with a mixed activity or an expanded substrate specificity were identified; their specificity-determining sequence motifs differed from the motifs of canonical TAs [7-9].

DAATs are spread among bacteria as the main enzymes of the synthesis of D-glutamate, an essential component of the cell wall. In vivo, DAATs catalyze the transfer of the amino group from D-alanine to $\alpha$-ketoglutarate, producing pyruvate and D-glutamate [10,11]. Only several DAATs are characterized today [12-17]. In vitro DAATs catalyze transamination between various $\mathrm{D}$-amino acids and keto acids, including $\alpha$-ketobyturate, indole-3pyruvate, $\alpha$-keto- $\gamma$-(methylthio)-butyrate, etc. [16]. However, $\alpha$-ketoglutarate and Dalanine remain the best substrates for most of the characterized DAATs $[12,13,15,16]$. DAATs are prominent for the industrial synthesis of optically pure D-amino acids. In the last few decades, several applications of DAATs for the synthesis of unnatural amino acids for clinical purposes have been proposed [18-22].

Specificity-determining sequence motifs for DAATs were identified by the analysis of the active site of DAATs from the bacteria of genus Bacillus. These DAATs are considered canonical. As observed for DAAT from Bacillus sp.YM-1 (bsDAAT), three residues in the active site, $\mathrm{Y} 31, \mathrm{R}^{*} 8^{*}$, and $\mathrm{H}_{100}$ ( $^{*}$ indicates residues from the adjacent subunit of the functional dimer), determine the specificity towards D-amino acids [3,17]. These residues form a "carboxylate trap" for the binding $\alpha$-carboxylic group of a substrate in a productive proD-position in the active site. However, the TA from Curtobacterium pusillum with an expanded substrate specificity [7], which catalyzes the synthesis of D-amino acids, using D-alanine or $(R)-(+)-1$-phenylethylamine (R-PEA) as amino donors, does not have a "carboxylate trap". Lysine and arginine residues, nonequivalent to the R98* and H100* of bsDAAT, can bind $\alpha$-carboxylic group in the active site. Thus, the question about the TA active site organization favoring efficient transamination of D-amino acids is still open and needs further consideration.

This study describes the identification, biochemical and structural characterization of a new D-amino acid transaminase from the bacterium Haliscomenobacter hydrossis (Halhy) [23]. Members of this species were isolated from freshwater lakes and ditch water. The optimal growth temperature and $\mathrm{pH}$ are $26^{\circ} \mathrm{C}$ and 7.5, respectively. The new TA is a strict DAAT and features the new specificity-determining sequence motifs in the active site within a conserved scaffold of TAs of PLP fold type IV. The detailed structural analysis of the new DAAT and a comparison with the previously studied DAATs allowed us to suggest the structural basis of the DAAT specificity in a more general form than is accepted today for DAATs' identification.

\section{Results}

\subsection{Enzyme Identification, Expression, and Purification}

Searching for sequences homologous to the sequence of TA from C. pusillum within the complete genome of H. hydrossis revealed a sequence of TA of PLP fold type IV (GenBank ID: WP_013764869.1), sharing sequence identity with TA from C. pusillum and bsDAAT $29.8 \%$ and $25.9 \%$, respectively. The sequence of the putative transaminase contained unique specificity-determining sequence motifs, which differ from the sequence motifs of the canonical TAs of PLP fold type IV (Table 1). 
Table 1. The specificity-determining sequence motifs of the canonical DAATs, BCATs, R-TAs, TA with an expanded substrate specificity from C. pusillum and TA from H. hydrossis (Halhy), according to Höhne et al. [6].

\begin{tabular}{|c|c|c|}
\hline \multirow{3}{*}{$\begin{array}{c}\begin{array}{c}\text { TA, } \\
\text { (Numbering Corresponds to) }\end{array} \\
\text { DAAT, } \\
\text { (DAAT from Bacillus sp. YM-1) }\end{array}$} & \multicolumn{2}{|c|}{ Specificity-Determining Sequence Motifs } \\
\hline & Motif 1 & Motif 2 \\
\hline & ${ }^{26} \mathrm{FxxxxYxV[IVA][KR]}{ }^{35}$ & ${ }^{86} \mathrm{HxY}^{88} \ldots{ }^{98}[\mathrm{RK}] \times \mathrm{H}^{100}$ \\
\hline $\begin{array}{c}\text { BCAT, } \\
\text { (BCAT from Escherichia coli) }\end{array}$ & ${ }^{31} Y x x x x F[E D] G x[K R]^{40}$ & ${ }^{95} \mathrm{YxR}^{97} \ldots{ }^{107}[\mathrm{LMVI}] \mathrm{G}[\mathrm{VL}]^{109}$ \\
\hline $\begin{array}{c}\text { R-TA, } \\
\text { (R-TA from Aspergillus terrus) }\end{array}$ & $\left.{ }^{55} \mathrm{HxxxxYD[VT]x[STAHP}\right]^{64}$ & $\begin{array}{l}{ }^{115}{\text { [FY]V[EQAWNS }]^{117} \ldots}^{128}{ }^{\text {[RKFGP]x [STANER] }}{ }^{130}\end{array}$ \\
\hline TA from C. pusillum & ${ }^{51}$ RxxxxFETIA $^{60}$ & ${ }^{115} \mathrm{GxK}^{117} \ldots{ }^{123}$ GIEGEGR $^{129}$ \\
\hline Halhy & ${ }^{28}$ RxxxxFDYFL $^{57}$ & ${ }^{88} \mathrm{GxR}^{90} \ldots{ }^{96} \mathrm{GYSPDGYTPVN}{ }^{106}$ \\
\hline
\end{tabular}

Halhy was cloned and expressed in a soluble form in E. coli and purified to homogeneity (Figure S1). The molecular weight of the purified Halhy was approximately $62 \mathrm{kDa}$, as determined by gel filtration, indicating Halhy as a homodimer with a small amount of a tetramer in solution (Figure S2). The absorption spectrum of the holo form of Halhy had two characteristic peaks: one at $280 \mathrm{~nm}$ and the other at $416 \mathrm{~nm}$ (Figure S3). The latter indicated the formation of a Schiff base with PLP. No shift of the peak maximum was observed within the $\mathrm{pH}$ range 4-10 (Figure S4), showing the stability of the protonated form of the Schiff base up to pH 10. This feature is characteristic of TAs of PLP fold type IV $[12,13,24]$.

\subsection{Enzyme Activity, Substrate Specificity, and Enantioselectivity}

The analysis of the activity of Halhy in the overall transamination reaction with the benchmark substrates of TA of PLP fold type IV showed a strong preferences for converting D-amino acids and no activity towards L-amino acids and (R)-PEA (Table 2) (Scheme 1).

Table 2. The activity of Halhy towards different amino donors in the overall transamination reaction.

\begin{tabular}{cccc}
\hline Amino Donor & Amino Acceptor & Initial Activity, U/mg & Assay \\
\hline D-alanine & $\alpha$-ketoglutarate & $50 \pm 3$ & LDH \\
D-leucine & & $0.70 \pm 0.08$ & HPLC \\
L-alanine & & $\mathrm{ND}$ & LDH \\
L-leucine & $\mathrm{ND}$ & HPLC \\
$(S)$-PEA & $\mathrm{ND}$ & Acetophenone assay \\
$(R)$-PEA & & $\mathrm{ND}$ & Acetophenone assay \\
\hline D-glutamate & pyruvate & $74 \pm 2$ & HGDH \\
$(S)$-PEA & & $\mathrm{ND}$ & Acetophenone assay \\
$(R)$-PEA & & $\mathrm{ND}$ & Acetophenone assay \\
\hline ND-not detected & &
\end{tabular}<smiles>C[C@H]([NH3+])C(=O)[O-]</smiles>

D-alanine

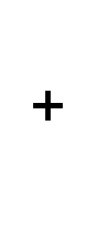<smiles>O=C([O-])CCC(=O)C(=O)[O-]</smiles>

$\alpha$-ketoglutarate

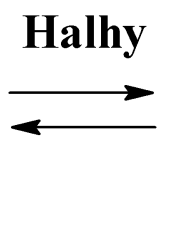

pyruvate<smiles>CC(=O)C(=O)[O-]</smiles>

Scheme 1. The enzymatic transamination reaction between D-alanine and $\alpha$-ketoglutarate.

The amino acceptor spectrum of Halhy was examined in the overall reaction using D-glutamate as an amino donor (Table 3). Halhy showed the highest activity towards 
pyruvate and $\alpha$-ketoglutarate, similar to the most characterized DAATs $[12,13,15]$. Notably, the Halhy activity in the overall reaction diminished with the increase of the length of the $\alpha$-keto acid side chain.

Table 3. The activity of Halhy in the overall reaction with D-glutamate and various $\alpha$-keto acids.

\begin{tabular}{cc}
\hline$\alpha$-Keto Acid & Initial Activity, U/mg \\
\hline pyruvate & $74 \pm 2$ \\
$\alpha$-ketoglutarate & $50 \pm 3$ \\
2-oxobutyrate & (with $5 \mathrm{mM} \mathrm{D-alanine)}$ \\
2-oxovalerate & $42 \pm 2$ \\
2-oxohexanoate & $15.0 \pm 0.4$ \\
3-metyl-2-oxovalerate & $0.320 \pm 0.005$ \\
4-metyl-2-oxovalerate & $0.085 \pm 0.004$ \\
phenylpyruvate & $0.220 \pm 0.007$ \\
\end{tabular}

The enantioselectivity of Halhy was evaluated in the synthesis of leucine and phenylalanine from keto analogs 4-methyl-2-oxovalerate or phenylpyruvate using D-glutamate as an amino donor. After 20 hours of the reaction at $30{ }^{\circ} \mathrm{C}$, product yield achieved $98.5 \%$ and $95.6 \%$ in leucine and phenylalanine production, respectively. The enantiomeric excess of D-leucine and D-phenylalanine amounted to $99.4 \%$ and $99.3 \%$, respectively (Supplementary, Figure S5).

\subsection{Effect of Temperature and $\mathrm{pH}$ on Enzyme Activity and Stability}

The effect of $\mathrm{pH}$ and temperature on the enzyme activity was examined in the overall reaction with $\mathrm{D}$-alanine and $\alpha$-ketoglutarate. In a $\mathrm{pH}$ range of 6.5-9.0 (Figure $1 \mathrm{~A})$, Halhy showed maximum activity at $\mathrm{pH}$ 8.0-8.5. The optimum temperature of the transamination reaction was found to be $40{ }^{\circ} \mathrm{C}$ (Figure 1B). The stability of Halhy was examined at 40 and $50{ }^{\circ} \mathrm{C}$ : the activity of Halhy remained unchanged at $40{ }^{\circ} \mathrm{C}$ for four days (Figure $1 \mathrm{C}$ ) and decreased $40 \%$ in a day at $50{ }^{\circ} \mathrm{C}$. The $T_{0.5}$ of the thermal unfolding of Halhy was $56.4 \pm 0.1^{\circ} \mathrm{C}$ (Figure 1D).

\subsection{Steady-State Kinetic Parameters of the Overall Transamination Reactions}

The kinetic parameters of the overall transamination reactions catalyzed by Halhy are given in Table 4. As seen, Halhy showed a high turnover rate both in the direct reaction with D-alanine and $\alpha$-ketoglutarate and in the reverse reaction with the D-glutamate and pyruvate (Scheme 1). The enzyme demonstrated the highest specificity towards $\alpha$ ketoglutarate and pyruvate. Among the amino donors, the best substrate was D-glutamate.

Table 4. The steady-state kinetic parameters of the overall transamination reaction catalyzed by wild-type Halhy (WT) and its R179G variant.

\begin{tabular}{|c|c|c|c|c|}
\hline Substrate & Cosubstrate & $k_{c a t}, \mathrm{c}^{-1}$ & $K_{m}, \mathrm{mM}$ & $\begin{array}{l}k_{c a t} / K_{m} \\
c^{-1} \mathbf{M}^{-1}\end{array}$ \\
\hline \multicolumn{5}{|c|}{ Wild-type Halhy } \\
\hline$\alpha$-ketoglutarate & $\begin{array}{c}\text { D-alanine } \\
40 \mathrm{mM}\end{array}$ & $146 \pm 4$ & $2.3 \pm 0.2$ & $63,000 \pm 7000$ \\
\hline D-alanine & $\begin{array}{c}\alpha \text {-ketoglutarate } \\
5 \mathrm{mM}\end{array}$ & $146 \pm 4$ & $23 \pm 1$ & $6300 \pm 400$ \\
\hline pyruvate & $\begin{array}{c}\text { D-glutamate } \\
4 \mathrm{mM}\end{array}$ & $215 \pm 6$ & $2.1 \pm 0.1$ & $103,000 \pm 8000$ \\
\hline D-glutamate & $\begin{array}{c}\text { pyruvate } \\
2.5 \mathrm{mM}\end{array}$ & $215 \pm 6$ & $10.3 \pm 0.7$ & $21,000 \pm 2000$ \\
\hline D-leucine & $\begin{array}{c}\alpha \text {-ketoglutarate } \\
5 \mathrm{mM}\end{array}$ & $10.5 \pm 0.4$ & $83 \pm 8$ & $130 \pm 20$ \\
\hline 4-methyl-2-oxovalerate & $\begin{array}{c}\text { D-alanine } \\
40 \mathrm{mM}\end{array}$ & $4.2 \pm 0.1$ & $70 \pm 6$ & $60 \pm 7$ \\
\hline
\end{tabular}


Table 4. Cont.

\begin{tabular}{|c|c|c|c|c|}
\hline Substrate & Cosubstrate & $k_{\text {cat }}, \mathrm{c}^{-1}$ & $K_{m}, \mathrm{mM}$ & $\begin{array}{r}k_{\text {cat }} / K_{m} \\
\mathbf{c}^{-1} \mathbf{M}^{-1}\end{array}$ \\
\hline \multicolumn{5}{|c|}{ R179G variant } \\
\hline$\alpha$-ketoglutarate & $\begin{array}{c}\text { D-alanine } \\
40 \mathrm{mM}\end{array}$ & $8.6 \pm 0.6$ & $8.1 \pm 0.8$ & $1100 \pm 200$ \\
\hline D-alanine & $\begin{array}{c}\alpha \text {-ketoglutarate } \\
5 \mathrm{mM}\end{array}$ & $8.6 \pm 0.6$ & $321 \pm 32$ & $27 \pm 5$ \\
\hline
\end{tabular}
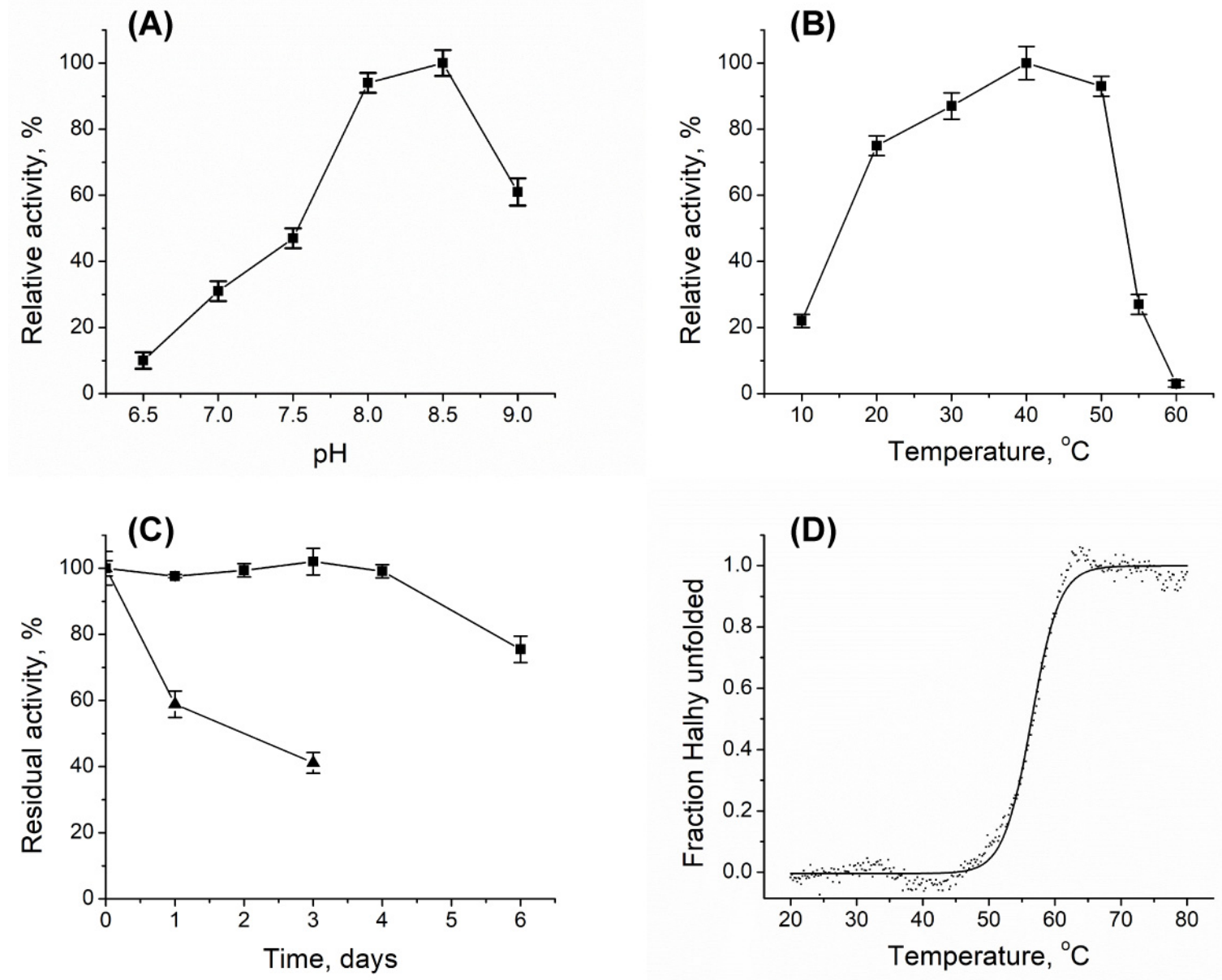

Figure 1. Kinetic and thermodynamic stability of WT Halhy. $(\mathbf{A}, \mathbf{B})$ the effects of $\mathrm{pH}$ and temperature on the overall transamination reaction with D-alanine and $\alpha$-ketoglutarate; $100 \%$ corresponds to $27 \pm 2 \mathrm{U} / \mathrm{mg}(\mathbf{A})$ and $50 \pm 3 \mathrm{U} / \mathrm{mg}(\mathbf{B})$. (C) The residual activity of Halhy incubating at $40{ }^{\circ} \mathrm{C}(\boldsymbol{\square})$ and $50{ }^{\circ} \mathrm{C}(\boldsymbol{\Delta}): 100 \%$ corresponds to $50 \pm 3 \mathrm{U} / \mathrm{mg}$ in the standard assay. Error bars represent standard deviation. (D) Thermal unfolding in K-phosphate buffer, pH 8.0.

\subsection{The Overall Structure of Halhy}

The structure of WT Halhy in the holo form with a covalently bound PLP was determined to $2.0 \AA$ resolution and deposited with PDB ID 7P7X. The subunit of Halhy has a structural organization typical of PLP-dependent TAs of fold type IV and is similar to the subunits of the known DAATs $[4,17]$. The Halhy subunit consists of two $\alpha / \beta$ domains: a small domain (residues 1-114) and a large domain (residues 128-281), connected by an interdomain loop (residues 115-127) (Figure 2A). The closest structural homologs of the Halhy subunit are subunits of BCATs (Table S1). Superposition of the subunits of Halhy and canonical bsDAAT showed less similarity with the corresponding RMSD between $\mathrm{C} \alpha$ of about $1.6 \AA$. 

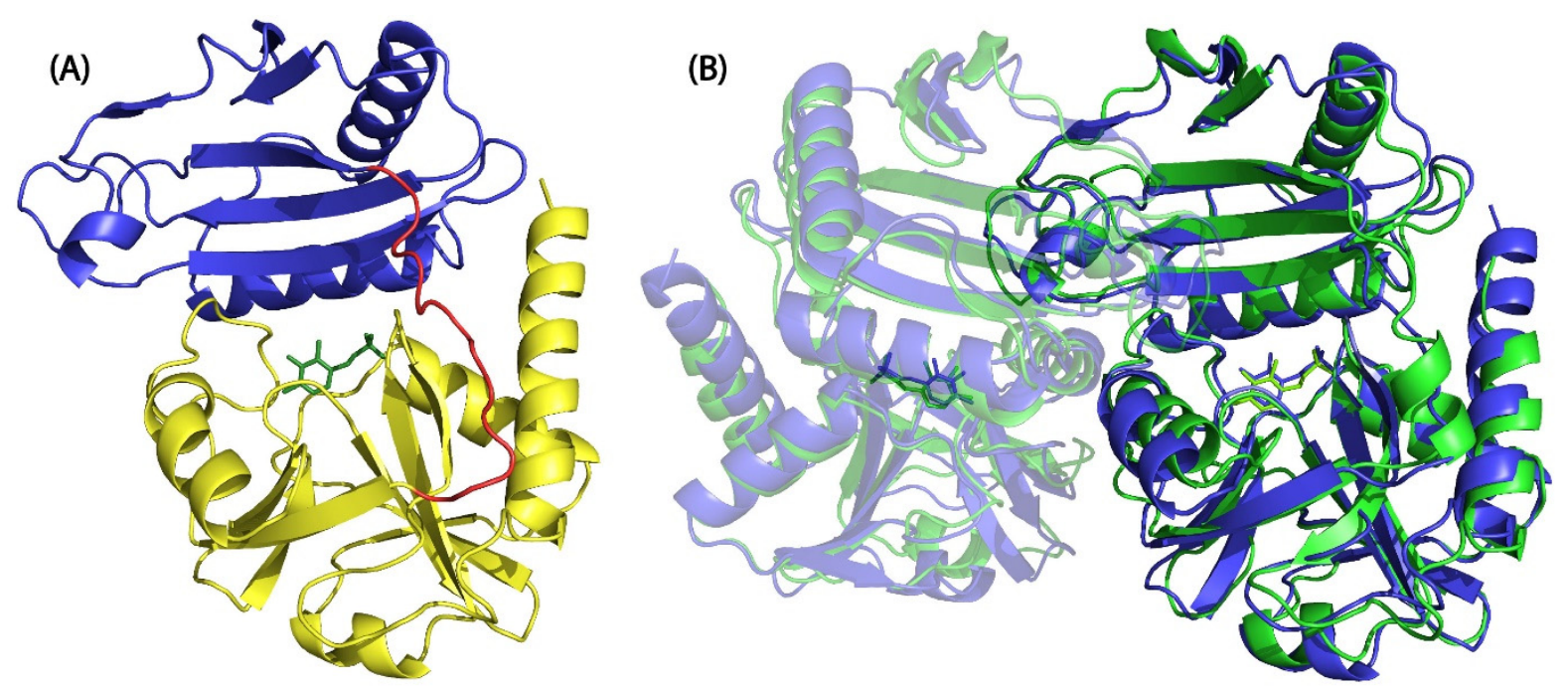

Figure 2. (A) The subunit of Halhy. The small domain is colored blue, the large domain is colored yellow, and the interdomain loop is colored red. The PLP molecule is shown as green sticks. (B) The active dimer of Halhy (blue) is superposed with the dimer of bsDAAT (green, PDB ID: 1DAA); the adjusted subunits of both structures are shown transparently.

The contact analysis showed that Halhy is a homodimer in the crystal. Its functional dimer is organized similarly to the dimers of TAs of PLP fold type IV (Figure 2B). The major differences between dimers of Halhy and canonical bsDAAT are observed in the looped regions (especially in the interdomain loop) and in the region 146-161 (Halhy numbering), which corresponds to the $\alpha$-helix of the large domain.

\subsection{The Active Site of Halhy}

The residues from both subunits form two symmetrical active sites in the dimer, with the PLP molecule covalently bound via a Schiff base to the catalytic K143. Additionally, PLP is coordinated by the conserved among TAs of PLP fold type IV residues: E176, forming a hydrogen bond with $\mathrm{N} 1$ atom of pyridine ring and R52, I202, T203, and T239, forming hydrogen bonds with the phosphate moiety of PLP. The phenyl oxygen atom of PLP forms a hydrogen bond with Y147 located on the $\alpha$-helix of the large domain. Noteworthy, this hydrogen bond is a hallmark of BCATs. In contrast, in bsDAAT as well as in DAATs from Burkholderia thailandensis (PDB ID: 4TM5) and Burkholderia cenocepacia (PDB ID: 4PBC), the phenyl moiety is coordinated through water molecule by a tyrosine residue (Y31 in bsDAAT) located on $\beta X$-strand of the small domain. However, in Halhy, this position in the $\beta X$-strand is occupied by F33, as in canonical BCATs.

Similar to the known TAs of PLP fold type IV, the active site of Halhy can be divided into two pockets: the O-pocket (near the phenyl moiety of PLP) and the P-pocket (near the phosphate moiety of PLP) (Figure 3) [4,25]. According to the enantioselectivity of Halhy, the $\alpha$-carboxylic group of substrates must be coordinated in the O-pocket, while their side groups must be coordinated in the P-pocket. The O-pocket of Halhy is confined by the side chains of residues F33, R28*, R90, and R179, forming a positively charged patch. The less positively charged O-pocket of bsDAAT is restricted by the side chains of residues Y31, R98* H100*, L149, and S180. The O-pocket loop of Halhy $\left({ }^{96}\right.$ GYSPDGYTPVN $\left.{ }^{106}\right)$ is shorter than that of bsDAAT $\left({ }^{94}\right.$ GTSPRAHQFPENTVK $\left.{ }^{108}\right)$ and does not include typical "carboxylate trap" residues-R98* and H100* (bsDAAT numbering). Instead, in Halhy, the side chains of R28* and R90 are directed into the "carboxylate trap" place and could bind the $\alpha$-carboxylic group of substrates. In bsDAAT, P-pocket is confined by V33, S240, T242, and K35, which is suggested to coordinate the $\gamma$-carboxylic group of $\alpha$-ketoglutarate [26]. The P-pocket of Halhy is lined by Y35, S238, and I240. Therefore, the P-pocket of Halhy is smaller than the P-pocket of bsDAAT. There are no positively charged residues in the P-pocket of Halhy, and the $\gamma$-carboxylic group can be coordinated by the side chain of S238 
and the backbone nitrogen atoms of the $\beta$-turn ${ }^{238}$ STIK $^{241}$. Interestingly, the amino acid composition of the $\beta$-turn of Halhy differs from that of the canonical DAATs and BCATs $\left({ }^{240}\right.$ STTS $^{243}$ in bsDAAT and ${ }^{256}$ GTAA $^{259}$ in BCAT from E. coli). The interdomain loop in the crystal structure of Halhy $\left({ }^{115}\right.$ DLPASAWEFSAQG $\left.{ }^{127}\right)$ is out of the active site, similarly to other DAATs (PDB ID: 1DAA, 4TM5, and 4PBC).

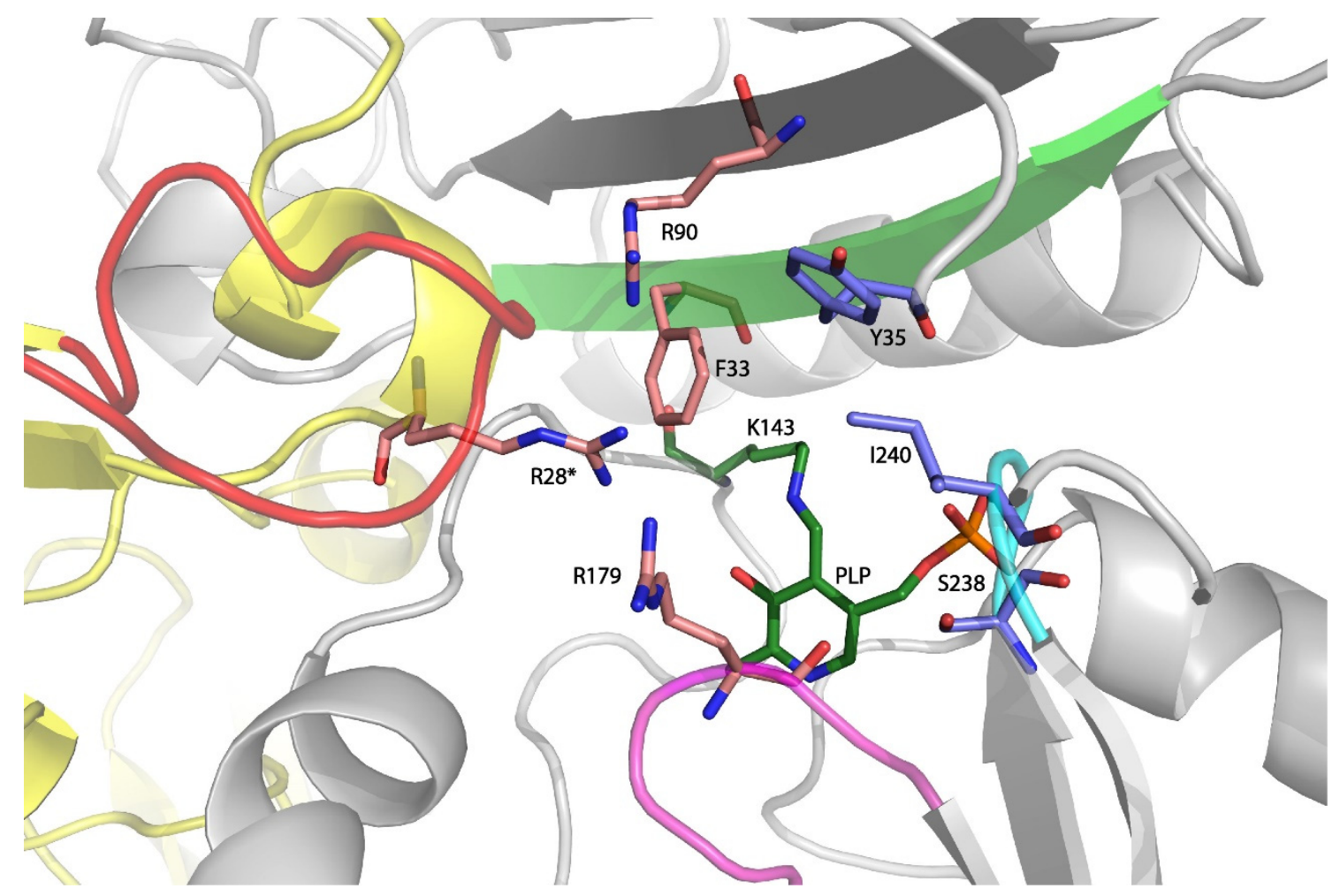

Figure 3. The active site of Halhy. The residues forming the O-pocket and the P-pocket are colored pink and blue, respectively; the PLP molecule and the catalytic lysine are colored dark green. The adjacent subunit is depicted in yellow. The $\beta$ X-stand and the $\beta$ Y-strand are colored green and black, respectively. The O-pocket loop is colored red. The $\beta$-turn ${ }^{238}$ STIK $^{241}$ and the $\beta$-turn ${ }^{177}$ SARS ${ }^{180}$ are colored cyan and magenta, respectively. The rest of the molecule is in grey.

To summarize, the active site of Halhy differs significantly from that of bsDAAT: the $\mathrm{P}$-pocket is smaller and does not have positively charged residues, the O-pocket does not have a "carboxylate trap," but instead has three positively charged residues (R28*, R90, and R179) possibly carrying a "carboxylate trap" function. The structural alignment of 27 homologous TAs (Appendix A) showed that four of them have positively charged residues in the R28* position, 19 TAs - in the R90 position, and only Halhy and uncharacterized TA (PDB ID: 6Q1R) have arginine residue in the R179 position in the $\beta$-turn ${ }^{177}$ SARS ${ }^{180}$, which is located above the PLP pyridine ring and confines the entrance into the active site through stacking interactions with Tyr102*. To further investigate the role of the unique R179, we constructed the R179G variant of Halhy: glycine was chosen as the most frequently occurred residue in this position (51\%) among comparing TAs (Appendix A).

\subsection{Characterization of the R179G Variant}

The R179G variant was expressed in a soluble form in E. coli and purified to homogeneity. The R179G variant eluted similarly to the WT Halhy (Figure S2). The kinetic and thermodynamic stability data of R179G are given in Figure 4. In the standard reaction, the R179G variant displayed the same pH optimum as WT (Figure 4A); however, the temperature optimum decreased to $30{ }^{\circ} \mathrm{C}$ (Figure $4 \mathrm{~B}$ ). At the same time, the R179G variant demonstrated stability at $40{ }^{\circ} \mathrm{C}, \mathrm{pH} 8.0$ (Figure $4 \mathrm{C}$ ); the thermal unfolding experiment showed $\mathrm{T}_{0.5}=55.7 \pm 0.1{ }^{\circ} \mathrm{C}$, which is nearly the same as for WT (Figure $4 \mathrm{D}$ ). The obtained 
stability data indicated the structural integrity of Halhy with the R179G substitution and some disturbances in the active site. According to the kinetic parameters of the overall transamination reaction given in Table 4, the R179G variant appeared to be much less active than WT in the optimal conditions. The obtained characteristics support the functional role of R179.
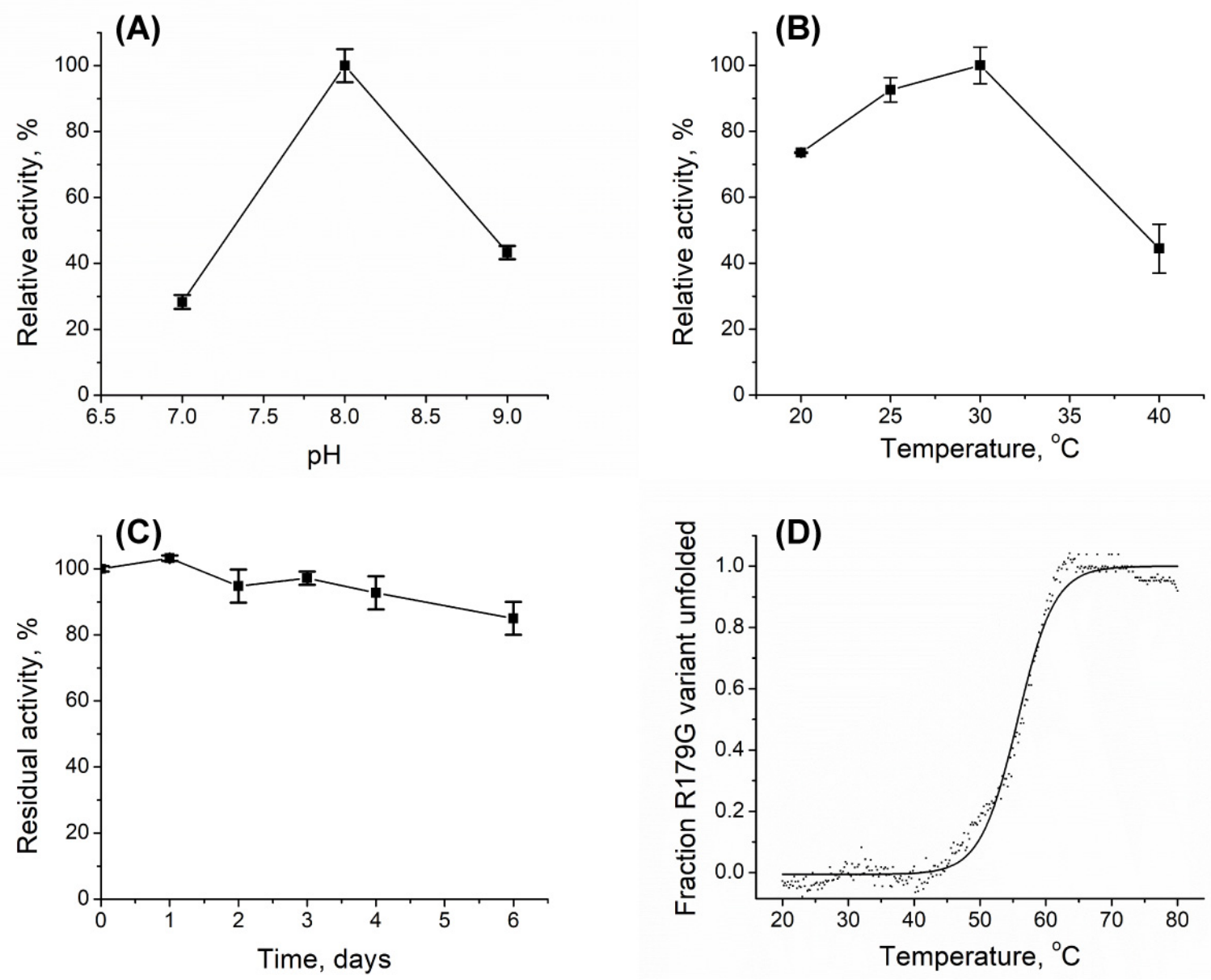

Figure 4. Kinetic and thermodynamic stability of the R179G variant. (A,B) The effects of $\mathrm{pH}$ and temperature on the overall reaction between D-alanine and $\alpha$-ketoglutarate; $100 \%$ corresponds to $0.20 \pm 0.01 \mathrm{U} / \mathrm{mg}(\mathbf{A})$ and $0.32 \pm 0.02 \mathrm{U} / \mathrm{mg}(\mathbf{B})$. (C) The residual activity of the R179G variant incubating at $40{ }^{\circ} \mathrm{C}, 100 \%$ corresponds to $0.32 \pm 0.02 \mathrm{U} / \mathrm{mg}$ in the standard assay. Error bars represent standard deviation. (D) Thermal unfolding in K-phosphate buffer, pH 8.0.

\subsection{D-Alanine Binding in the Active Site of the WT Halhy and Its R179G Variant}

According to the steady-state kinetic experiments (Table 4), the R179G substitution led to a 17-fold decrease in $k_{\text {cat }}$ and a 14-fold increase in $K_{m}$ of D-alanine. These changes might indicate worse binding of the substrate in the active site. We analyzed MD trajectories of the enzyme-substrate complexes (ES complexes) of the WT Halhy or the R179G variant with D-alanine to quantify these changes. We found that hydrogen bonds between the $\alpha$-carboxylic group of D-alanine and the side chain of $\mathrm{R} 28^{*}$ were formed in both model systems (Figure 5). Therefore, we suppose that R28* is responsible for the proper D-alanine binding in the ES complexes. We observed that R90 formed a hydrogen bond with the $\alpha$-carboxylic group around half of the simulation time, and R179 did not interact with D-alanine during the simulations. Generally, hydrogen bonds between D-alanine and R28* are more stable in the WT Halhy. One hydrogen bond is observed during all simulations ( $>98 \%$ for both subunits), and two hydrogen bonds with the NH2 group exist for longer than half of the simulation time. In the R179G variant, no hydrogen bonds exist during the whole simulation, resulting in the increased flexibility of the substrate. In the active 
site of WT Halhy, the side chain of D-alanine is located in the P-pocket (see $C_{\beta}$ atoms in Figure 6A,C), which is in line with the previous studies [3,27]. The P-pocket location corresponds to the dihedral angle $\mathrm{C}_{\beta}-\mathrm{C}-\mathrm{N}-\mathrm{H}$ values between 100 and 180 degrees. In contrast, the side chain of D-alanine is highly flexible in the ES complex of the R179G variant (Figure $6 \mathrm{~B}, \mathrm{C}$ ) and occupies both $\mathrm{P}$ - and O-pockets during the simulations. These findings explain the decrease in the catalytic activity of the R179G variant and worse binding in the active site.
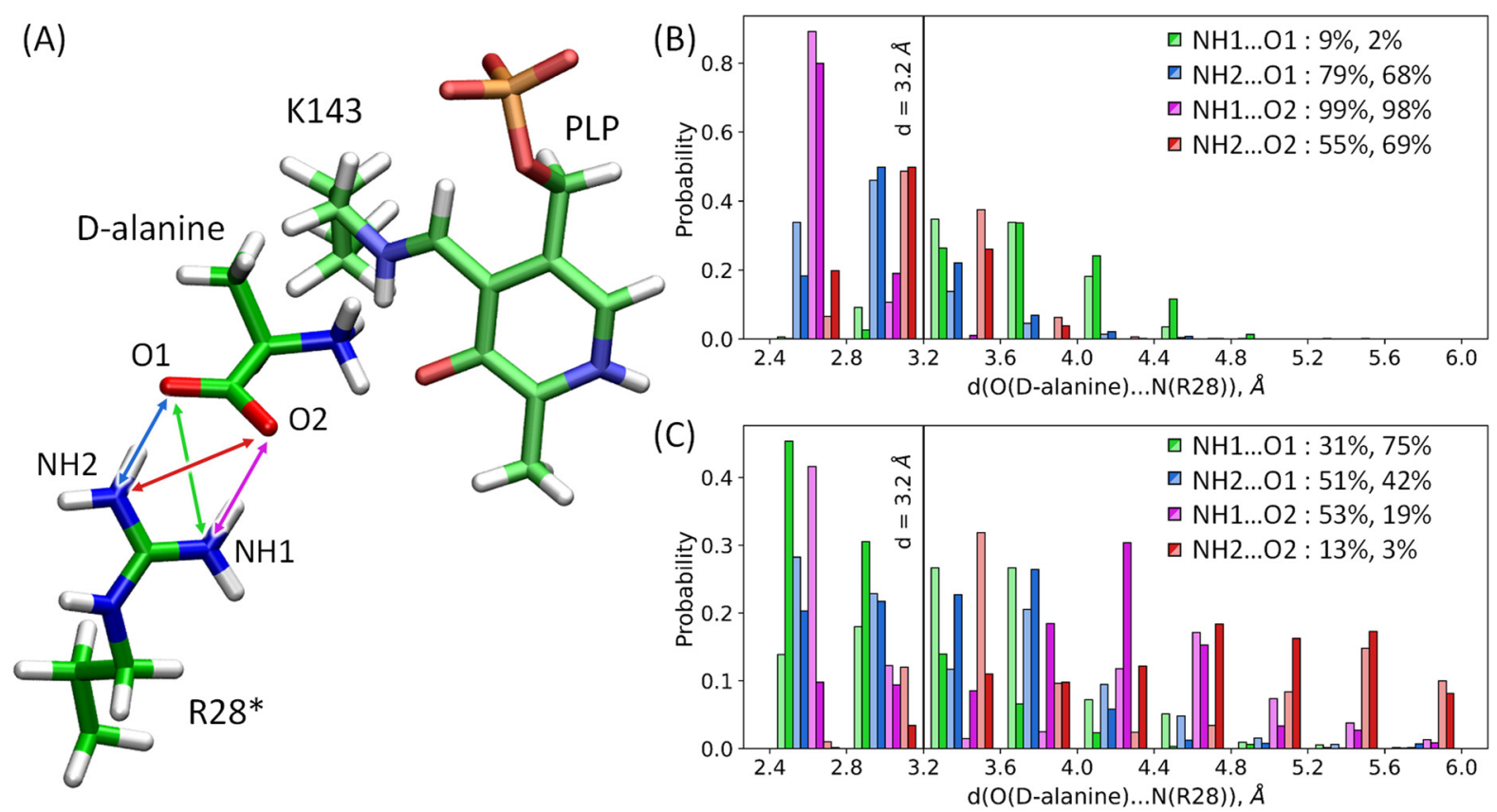

Figure 5. (A) A part of the Halhy active site composed of the protonated Schiff base formed by K143 and PLP and R28* with the bound substrate, D-alanine. The hydrogen bond distances measured between nitrogen and oxygen atoms are colored following the histograms. Probability distributions of the hydrogen bond distance in the WT Halhy (B) and the R179G variant (C). Darker and lighter bars of the same color correspond to the different subunits of the functional dimer. Values in percentages show the fractions of MD trajectories when the hydrogen bonds are formed (the criterion is the distance between the non-hydrogen atoms less than $3.2 \AA$ ). The values for the subunits are given separately. Here and in Figure 6 , the color code for molecular models is the following: carbon-green, oxygen—red, nitrogen—blue, hydrogen—white, and phosphorus-orange.
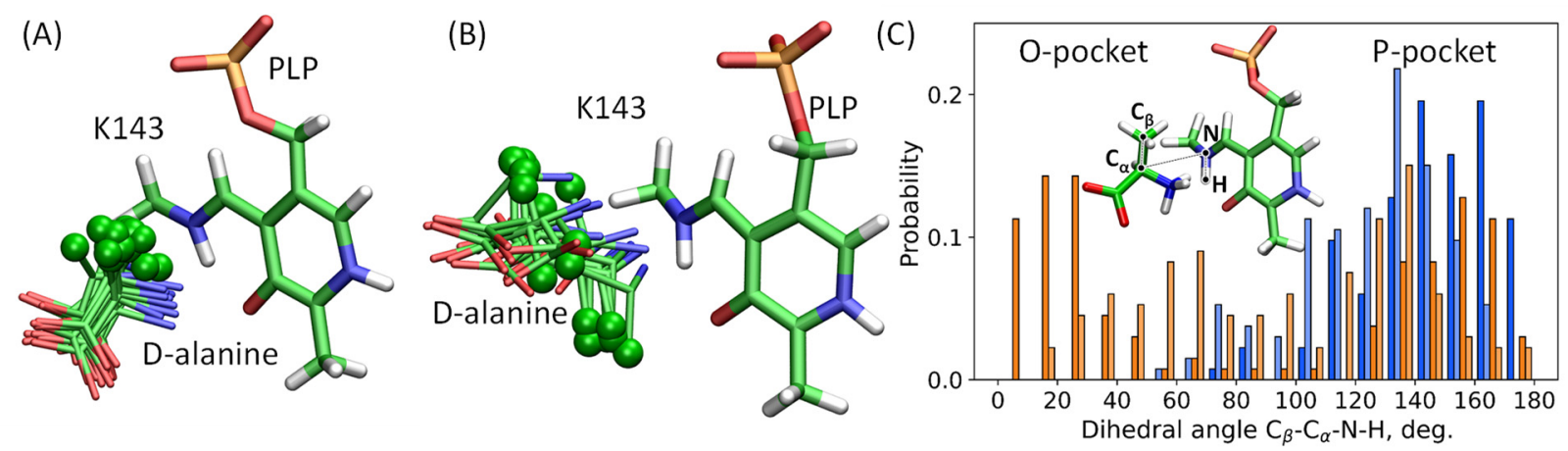

Figure 6. Alignment of multiple frames from the MD runs of the ES complex of WT Halhy (A) and the R179G variant (B) with D-alanine. (C) Distributions of dihedral angles illustrating the orientation of D-alanine. Smaller values correspond to the side chain binding to the O-pocket, larger values- to the P-pocket. Blue bars are for the WT Halhy and orange for the R179G variant. Darker and lighter bars of the same color correspond to the different subunits. 


\section{Discussion}

The PLP-dependent transaminase from H. hydrossis, Halhy, is a strict DAAT, active towards D-glutamate, aliphatic and aromatic D-amino acids, and corresponding keto acids. Halhy is distinguished by the high conversion rate of $\alpha$-ketoglutarate and D-glutamate under reaction conditions typical of known DAATs: $\mathrm{pH} 8.0-8.5$ at $30-40^{\circ} \mathrm{C}$. The functional unit of Halhy is a dimer similar to the dimers of canonical TAs of PLP fold type IV. The Halhy active site comprises several features of canonical BCATs and DAATs. The hydrogen bond between Y147 and phenyl oxygen of PLP, R90 in $\beta Y$-strand in the O-pocket and lack of charges in the P-pocket are typical of BCATs, while a loose interdomain loop and a positively charged patch for $\alpha$-carboxylic group binding in the O-pocket are typical of DAATs. However, the Halhy active site differs significantly in the composition of amino acids from known BCATs and DAATs. A new approach for the proD-coordination of substrates can be observed in Halhy: (1) two arginine residues (R28* and R90) can bind an $\alpha$-carboxylic group of a substrate; (2) a unique R179 participates in the substrate binding and can control the active site entrance; (3) no positive charges in the P-pocket; however, the residues from $\beta$-turn ${ }^{238}{ }^{S T I K}{ }^{241}$ can orient properly $\gamma$-carboxylic group of D-glutamate $/ \alpha$ ketoglutarate (the side chain of K241 is out of the P-pocket). Finally, residues from the O-pocket loop and the interdomain loop seem not to participate in substrate binding. Earlier, a tandem of arginine and lysine residues in the O-pocket instead of "carboxylate trap" was observed in the active site of the TA from C. pusillum (PDB ID: 5K3W) [7], which catalyzed the transamination between D-amino acids or $(R)$-amines and $\alpha$-keto acids. Another common feature of the active sites of Halhy and TA from C. pusillum is an unshaped P-pocket with the interdomain loop aside of it and positively charged residue on the $\beta$-turn $\left({ }^{238}\right.$ STIK $^{241}$ and ${ }^{270}$ SSVR $^{273}$, respectively). However, the O-pocket loop (its amino acid composition) and the active site entrance of TA from C. pusillum differ significantly from that of Halhy and canonical BCATs.

In summary, Halhy is a "high quality" DAAT, and its activity and specificity are achieved at the active site of a unique amino acid composition. We suppose that the DAATlike specificity among TAs of PLP fold type IV can be achieved at active sites of various amino acid compositions, but having at least two important structural features. These are a strong positively charged patch in the O-pocket (a "carboxylate trap" of various amino acid compositions) and the unshaped P-pocket with an unconserved coordination site for the $\gamma$-carboxylic group of $\alpha$-ketoglutarate

\section{Materials and Methods}

\subsection{Cloning, Expression, and Purification of the Recombinant Halhy and Its R179G Variant}

The gene Halhy_2446 encoding transaminase of PLP fold type IV was identified in the complete genome sequence of $H$. hydrossis using TA with an expanded substrate specificity from C. pusillum [7] as a query sequence. The nucleotide sequence of Halhy_2446 was optimized for expression in E. coli using server Optimizer (http:/ / genomes.urv.es/ OPTIMIZER/) and synthesized by ATG Service Gene (St. Petersburg, Russia) with overhangs complementing the NdeI and HindIII restriction sites attached to the $5^{\prime}$ and $3^{\prime}$-ends, respectively. The synthetic gene was cloned into the pET-21d vector (Novagen, Darmstadt, Germany) modified as described by Boyko et al. [28]. Recombinant Halhy (281 a.a., 32.09 $\mathrm{kDa}$ ) fused at the $\mathrm{N}$-terminus to a His6TEV-tag was expressed in E. coli Rosetta(DE3) pLysS cells (Novagen, Darmstadt, Germany). Transformed cells were grown in LB high salt medium, containing $100 \mu \mathrm{g} / \mathrm{ml}$ ampicillin and $34 \mu \mathrm{g} / \mathrm{ml}$ chloramphenicol (PanreacAppliChem, Darmstadt, Germany) at $37^{\circ} \mathrm{C}$ until the OD600 value reached 0.8, and the expression was induced with $0.2 \mathrm{mM} \mathrm{IPTG}$. After incubation for $18 \mathrm{~h}$ at $25^{\circ} \mathrm{C}$, the cells were harvested by centrifugation, resuspended in $50 \mathrm{mM}$ Tris- $\mathrm{HCl}$ buffer, $\mathrm{pH}$ 8.0, supplemented with $500 \mathrm{mM} \mathrm{NaCl}, 20 \mathrm{mM}$ imidazole, $1 \mathrm{mM}$ b-mercaptoethanol, $0.1 \%(v / v)$ Triton X-100, $100 \mu \mathrm{M}$ PLP, and $1 \mathrm{mM}$ PMSF, and disrupted by sonication. The crude cell extract was centrifuged for $25 \mathrm{~min}$ at 18,500 $\times \mathrm{g}$. The supernatant was applied to a HisTrap HP column (Cytiva, Marlborough, MA, USA), equilibrated in a binding buffer (50 mM 
Tris- $\mathrm{HCl}$ buffer, $\mathrm{pH}$ 8.0, supplemented with $500 \mathrm{mM} \mathrm{NaCl}, 20 \mathrm{mM}$ imidazole, and $0.1 \%$ $(v / v)$ Triton X-100). The (His)6-tagged recombinant Halhy was eluted with a linear gradient from 20 to $500 \mathrm{mM}$ imidazole in the same buffer without Triton X-100. The active pool was incubated for $1 \mathrm{~h}$ with a ten-fold molar excess of PLP at $+4{ }^{\circ} \mathrm{C}$, then concentrated with a $30 \mathrm{kDa}$ cut-off centrifugal filter device (Millipore, Burlington, MA, USA) and transferred into $50 \mathrm{mM}$ Tris-HCl buffer, $\mathrm{pH}$ 8.0, supplemented with $100 \mathrm{mM} \mathrm{NaCl}, 1 \mathrm{mM}$ EDTA, $1 \mathrm{mM}$ $\beta$-mercaptoethanol, $5 \%(v / v)$ glycerol, and TEV protease (1 $\mathrm{mg}$ per $10 \mathrm{mg}$ of the protein). The solution was incubated for $2 \mathrm{~h}$ at room temperature, dialyzed against the binding buffer, and applied to a HisTrap HP column. TEV protease and a cleaved His-tag were absorbed on the column, and the flow-through was concentrated and applied to a Superdex 200 10/300 GL column (Cytiva, Marlborough, MA, USA) equilibrated in 50 mM HEPES buffer, pH 7.5, supplemented with $100 \mathrm{mM} \mathrm{NaCl}, 1 \mathrm{mM}$ DTT, and $100 \mu \mathrm{M}$ PLP. Active fractions of Halhy were stored at $-20{ }^{\circ} \mathrm{C}$ with glycerol added to a final concentration of $50 \%$. The protein purity was analyzed by SDS-PAGE $(12 \%)$. The protein concentration was determined spectrophotometrically [29].

The $\mathrm{R} 179 \mathrm{G}$ variant of Halhy was created by easy single-primer site-directed mutagenesis as described in $[30,31]$. Eighteen cycles of PCR amplification were performed on an expression plasmid carrying Halhy_2446 gene using Tersus Plus PCR kit (Evrogen, Moscow, Russia) and a mutagenesis primer $5^{\prime}$-AGGAAGAAGTTAGAGCCAGCGCTTTCACGAATCC-3' ${ }^{\prime}$, the mutation is underlined. Amplified fragments were treated with the DpnI (Thermo Fisher Scientific, Waltham, MA, USA) restriction enzyme to eliminate the methylated DNA template, and were then transformed to E. coli Mach I cells. Clones carrying target mutation were identified by colony PCR assay performed using Taq DNA polymerase and the pair of primers consisting of T7 universal forward primer and check primer 5'-CAGGAAGAAGTTAGAGCC$3^{\prime}$. To verify the introduced mutation and ensure the absence of random mutations associated with PCR, selected clones were sequenced on an ABI 3730xl DNA Analyzer (Applied Biosystems, Foster City, CA, USA). The R179G variant production and purification were performed as described for wild-type Halhy.

The (R)-2-hydroxyglutarate dehydrogenase (HGDG) from Acidaminococcus fermentans was produced and purified similarly. The purified enzyme was desalted in $100 \mathrm{mM}$ K-phosphate buffer, $\mathrm{pH} 8$, and stored at $-20{ }^{\circ} \mathrm{C}$ in $50 \%$ glycerol.

The amino acid sequences were checked by MALDI-TOF MS analysis (UltraFlextreme Bruker Daltonik, Bremen, Germany).

\subsection{Enzyme Activity Assay}

The overall transamination reaction with $\mathrm{D}$-amino acids was assayed at $40{ }^{\circ} \mathrm{C}$ by coupled enzyme reaction using lactate dehydrogenase (LDH) (Sigma, St. Louis, MO, USA) to detect pyruvate production. Standard assay solution contained $50 \mathrm{mM} \mathrm{K}$-phosphate buffer, $\mathrm{pH} 8,30 \mu \mathrm{M}$ PLP, $5 \mathrm{mM}$ D-alanine and $2 \mathrm{mM} \alpha$-ketoglutarate, $330 \mu \mathrm{M}$ NADH, and $2 \mathrm{U} / \mathrm{mL} \mathrm{LDH}$. When D-glutamate was taken in the transamination reaction, $4 \mathrm{U} / \mathrm{mL}$ HGDH was applied to detect $\alpha$-ketoglutarate production, the reaction mixture contained $50 \mathrm{mM}$ K-phosphate buffer, $\mathrm{pH}$ 8, $30 \mu \mathrm{M}$ PLP, $5 \mathrm{mM}$ D-glutamate and $2 \mathrm{mM} \alpha$-keto acid, and $330 \mu \mathrm{M}$ NADH. The reaction was initiated by adding $0.01-10 \mu \mathrm{M}$ of the purified Halhy. The reaction progress was monitored by detection the decrease in the absorbance $\left(\varepsilon_{\mathrm{NADH}}=6220 \mathrm{M}^{-1} \mathrm{~cm}^{-1}\right)$ at $340 \mathrm{~nm}$, using SPECTROstar Omega (BMG Labtech $\mathrm{GmbH}$, Ortenberg, Germany). For measuring the activity at $50{ }^{\circ} \mathrm{C}$ and above, and a $\mathrm{pH}$ above 8.5, the pyruvate formation was monitored using a discontinuous lactate dehydrogenase assay at $25^{\circ} \mathrm{C}$, in $100 \mathrm{mM} \mathrm{K}$-phosphate buffer, $\mathrm{pH} 7.0$ [32]. The activity of Halhy was calculated from the initial linear region of the progress curve of the reaction. One unit (U) was defined as the amount of the enzyme that catalyzed the conversion of $1 \mu \mathrm{mol}$ of the substrate into a product per minute.

Steady-state kinetic parameters of the direct reaction between D-alanine and $\alpha$ ketoglutarate and the reverse reaction between D-glutamate and pyruvate were determined from the substrate saturation curves at the constant co-substrate concentration at 
$40{ }^{\circ} \mathrm{C}$. Saturation curves were analyzed using the Michaelis-Menten model. The kinetic parameters were calculated by fitting the initial velocity data to Equation (1):

$$
V=\frac{V_{m} \times A \times B}{K_{M}^{A} \times B+K_{M}^{B} \times A+A \times B}
$$

where $V$ is the initial velocity, $V_{m}$ is the maximum velocity, $A$ and $B$ are substrate concentration, and $K_{M}^{A}$ and $K_{M}^{B}$ are the $K_{M}$ of substrates $A$ and $B$, respectively. All measurements were performed at least in triplicate. The data were analyzed using Origin 8.0 software (OriginLab, Northampton, MA, USA). The activity of the R179G variant was measured in the same way at $25^{\circ} \mathrm{C}$.

The activity towards $(S)-(-)$ - and $(R)-(+)-1$-phenylethylamine (PEA) was measured spectrophotometrically at $40{ }^{\circ} \mathrm{C}$ by the acetophenone assay [33], using Evolution $300 \mathrm{UV}-\mathrm{Vis}$ spectrophotometer (Thermo Scientific, Waltham, MA, USA). The assay mixture contained $50 \mathrm{mM}$ CHES buffer, pH 9, $30 \mu \mathrm{M}$ PLP, $5 \mathrm{mM}$ amine, and $2 \mathrm{mM} \alpha$-ketoglutarate or pyruvate. An extinction coefficient $(\varepsilon)$ of $11,600 \mathrm{M}^{-1} \mathrm{~cm}^{-1}$ was used for acetophenone. One activity unit was defined as the amount of the enzyme necessary to form $1 \mu \mathrm{M}$ of acetophenone per minute.

The activity towards D-leucine and L-leucine was measured chromatographically by analyzing the production of 4-methyl-2-oxovalerate. The assay mixture contained $50 \mathrm{mM}$ K-phosphate buffer, $\mathrm{pH} 8,30 \mu \mathrm{M}$ PLP, $5 \mathrm{mM}$ D- or L-leucine, and $2 \mathrm{mM} \alpha$-ketoglutarate at $40{ }^{\circ} \mathrm{C}$. The reaction was initiated by the addition of $1.2 \mu \mathrm{M}$ Halhy. The aliquots were taken at 10 minute time intervals. The reaction was terminated by heating up to $95{ }^{\circ} \mathrm{C}$ for $5 \mathrm{~min}$, followed by centrifugation at $10,000 \times g$ for $10 \mathrm{~min}$. The aliquots were applied to the $\mathrm{C} 18$ column (Zorbax Eclipse XDB-C18, $5 \mu \mathrm{m}, 4.6 \times 150$ mm, (Agilent Technologies, Inc., Santa Clara, CA, USA)). The column was equilibrated in $20 \mathrm{mM} \mathrm{KH}_{2} \mathrm{PO}_{4}, \mathrm{pH} 3$, containing 15\% methanol, at $1.0 \mathrm{ml} / \mathrm{min}, 25^{\circ} \mathrm{C}$. The product accumulated during the reaction was eluted with the same retention time $(8.6 \mathrm{~min})$ as the control 4-methyl-2-oxovalerate sample. One unit (U) was defined as the amount of the enzyme necessary to form $1 \mu$ mol 4-methyl-2oxovalerate per minute.

\subsection{Effect of $p H$ and Temperature on the Transamination Reaction}

The optimal $\mathrm{pH}$ and temperature were determined for the overall transamination reaction between $5 \mathrm{mM}$ D-alanine and $2 \mathrm{mM} \alpha$-ketoglutarate. The Halhy activity was measured in a mixed buffer containing $50 \mathrm{mM}$ Tris- $\mathrm{HCl}$ and $50 \mathrm{mM} \mathrm{K-phosphate,} \mathrm{pH} \mathrm{6-9,}$ supplemented with $30 \mu \mathrm{M}$ PLP at $30^{\circ} \mathrm{C}$. The optimal temperature was determined at a temperature range from 15 to $60^{\circ} \mathrm{C}$ in $50 \mathrm{mM}$ K-phosphate buffer, $\mathrm{pH}$ 8.0, and $30 \mu \mathrm{M}$ PLP.

\subsection{Analysis of Halhy Thermal Stability}

The thermal stability was determined by incubating $30 \mu \mathrm{M}$ Halhy at $40{ }^{\circ} \mathrm{C}$ in $50 \mathrm{mM}$ K-phosphate buffer, pH 8.0, containing $50 \mathrm{mM} \mathrm{NaCl}$ and $100 \mu \mathrm{M}$ PLP. Residual activity was measured in the standard assay at regular intervals for six days.

The thermal unfolding was studied using circular dichroism spectroscopy. Molar ellipticity [ $\theta$ ] changes at $208 \mathrm{~nm}$ were measured for $10 \mu \mathrm{M}$ Halhy in $50 \mathrm{mM}$ K-phosphate buffer, $\mathrm{pH} 8$, in a 1-mm optical path cuvette using a Chirascan instrument, equipped with a Peltier thermostatic cell holder (Applied Photophysics, Surrey, UK). Heating from 20 to $80{ }^{\circ} \mathrm{C}$ was carried with $1{ }^{\circ} \mathrm{C} / \mathrm{min}$. The midpoint temperature of thermal denaturation $\left(\mathrm{T}_{0.5}\right)$ was calculated using Boltzmann's equation.

\subsection{Analysis of the Product Yield and Enantiomeric Excess in the Transamination Reaction}

The product yield was determined by monitoring the consumption of 4-methyl2-oxovalerate in reaction 4-methyl-2-oxovalerate + D-glutamate or the production of Dphenylalanine in the reaction phenylpyruvate $+D$-glutamate. A one-pot three-enzyme system was employed to shift the equilibrium of the reaction towards the products. In this process, the coproduct, $\alpha$-ketoglutarate, was removed from the reaction medium by HGDG assay, 
accompanied by NADH recovery using glucose dehydrogenase reaction with glucose. The reaction mixture contained $100 \mathrm{mM}$ K-phosphate buffer, pH 7.5, $100 \mu \mathrm{M}$ PLP, $50 \mathrm{mM}$ D-glutamate, $50 \mathrm{mM}$ 4-methyl-2-oxovalerate or $50 \mathrm{mM}$ phenylpyruvate, $1 \mathrm{mM} \mathrm{NADH}$, $150 \mathrm{mM}$ D-glucose, $90 \mathrm{U} \mathrm{HGDH}$, and $50 \mathrm{U}$ glucose dehydrogenase (Sigma, St. Louis, $\mathrm{MO}, \mathrm{USA})$. The reaction mixtures were incubated at $30^{\circ} \mathrm{C}$ for $20 \mathrm{~h}$. The reactions were terminated by removing the enzyme using an Amicon-Ultra-15 centrifugal tube (Millipore, Burlington, MA, USA), and then aliquots were analyzed by HPLC (ÄKTA Purifier, Cytiva, Marlborough, MA, USA).

4-Methyl-2-oxovalerate and D-phenylalanine were directly detected by HPLC using a reverse-phase C18 column (Zorbax Eclipse XDB-C18, $5 \mu \mathrm{m}, 4.6 \times 150 \mathrm{~mm}$, (Agilent Technologies, Inc., Santa Clara, CA, USA)) with a UV detector set at $210 \mathrm{~nm}$. The column was equilibrated in $20 \mathrm{mM} \mathrm{KH}_{2} \mathrm{PO}_{4}, \mathrm{pH} 3$, containing $15 \%$ methanol, at $1.0 \mathrm{~mL} / \mathrm{min}$, and at $25{ }^{\circ} \mathrm{C}$. Retention times of pure 4-methyl-2-oxovalerate and D-phenylalanine were 8.6 and $4.3 \mathrm{~min}$, respectively.

The chiral analysis of produced D-leucine and D-phenylalanine was performed by HPLC using a reverse-phase C18 column with a UV detector set at $340 \mathrm{~nm}$. Deproteinized samples were derivatized with Marfey's reagent (Sigma, St. Louis, MO, USA) [34].

\subsection{Crystallization and Data Collection}

The holo form of the Halhy was crystallized by the "hanging drop" vapor diffusion method in 24-well VDX plates (Hampton Research, Aliso Viejo, CA, USA). A total of $1.5 \mu \mathrm{L}$ of protein $(15 \mathrm{mg} / \mathrm{mL})$ was mixed with $1.5 \mu \mathrm{L}$ of precipitant containing $0.1 \mathrm{M}$ Sodium acetate buffer, $\mathrm{pH} 4.8$, and 18\% PEG3350 and set up over $500 \mu \mathrm{l}$ of precipitant in a sealed reservoir. Before data collection, crystals were briefly soaked in the mother liquor containing $25 \%$ glycerol as a cryoprotectant. The crystals were then flash-cooled to $100 \mathrm{~K}$ in liquid nitrogen. The X-ray diffraction data were collected at the ID30A-3 beamline of the ESRF synchrotron (Grenoble, France). The data were indexed, integrated, and scaled using Dials [35]. The program Pointless [36] suggested a C2 space group with one subunit per asymmetric unit. The data collection and processing statistics are summarized in Table 5.

\subsection{Structure Solution and Refinement}

Halhy structure was solved by the molecular replacement method using the Molrep program [37] with the atomic coordinates of the branched-chain aminotransferase from Geoglobus acetivorans (PDB ID: 5E25) as a starting model. The refinement of the structure was carried out using the REFMAC5 program of the CCP4 suite [38]. The visual inspection of electron density maps and the manual rebuilding of the model was carried out using the COOT interactive graphics program [39]. A resolution was cut to $2.0 \AA$ during the refinement to reduce the noise of the maps and achieve better R-factors. The refinement statistic is given in Table 5. In the final model, an asymmetric unit contained one independent copy of the protein with 282 visible residues and covalently bound PLP molecule (Supplementary Figure S8), 171 water molecules, one phosphate, and one acetate ion from the buffer and crystallization solution, correspondingly.

The visual inspection of the modeled structures and figure preparation were carried out by the COOT program [39] and the PyMOL Molecular Graphics System, Version 2.4. (Schrödinger, New York, NY, USA). The structure comparison and superposition were made using the PDBeFOLD program [40]. The contacts were analyzed using the PDBePISA [41].

\subsection{Molecular Modeling}

Molecular dynamics simulations were performed using NAMD3 software [42]. A crystal structure obtained in this study was utilized as a source of coordinates of nonhydrogen atoms. Protonation states of amino acid residues were as follows: positively charged $\mathrm{R}$ and $\mathrm{K}$, negatively charged $\mathrm{E}$ and $\mathrm{D}$, and neutral $\mathrm{H}$. The system was solvated in a rectangular water box so that the distance from the protein surface to the border of the cell exceeded $12 \AA$. Protein macromolecule was composed of two subunits, and it was 
described using CHARMM36 force field [43,44] and water molecules with the TIP3P force field parameters [45]. Force field parameters for the PLP molecules were obtained on the web service (https:/ / cgenff.umaryland.edu/) that automatically assigns atom types of the CGenFF to all atoms [46]. We obtained a patch to describe a protonated Schiff base formed by the PLP and the K143 of the transaminase. We compared the dynamic behavior of the WT and R179G variant of Halhy complexed with the D-alanine substrate in the active site (ES complex). To model ES complexes within the classical force field parameters, we added harmonic potentials to the following distances: a distance between the hydrogen atom of the protonated amino group of D-alanine and a nitrogen atom of the protonated Schiff base with the $\xi_{0}=2 \AA$ and $K=40 \mathrm{kcal} / \mathrm{mol} / \AA^{2}$, a distance between the nitrogen atom of D-alanine and the carbon atom of the protonated Schiff base with the $\xi_{0}=3.2 \AA$ and $\mathrm{K}=40 \mathrm{kcal} / \mathrm{mol} / \AA^{2}$. The NPT ensemble was utilized with $p=1 \mathrm{~atm}$ and $\mathrm{T}=300 \mathrm{~K}$ with the $1 \mathrm{fs}$ integration time step; the total length of the MD trajectory for each model system was 200 ns. Cutoff distances for all non-covalent interactions were $12 \AA$ with the switch to the smoothing potential at $10 \AA$.

Table 5. Data collection, processing, and refinement.

\begin{tabular}{|c|c|}
\hline Diffraction Source & ID30A-3, ESRF \\
\hline Wavelength $(\AA)$ & 0.97 \\
\hline Temperature (K) & 100 \\
\hline Detector & Eiger X 4M \\
\hline Crystal-to-detector distance (mm) & 131.78 \\
\hline Rotation range per image $\left(^{\circ}\right)$ & 0.2 \\
\hline Total rotation range $\left(^{\circ}\right)$ & 160 \\
\hline Space group & $\mathrm{C} 2$ \\
\hline$a, b, c(\AA)$ & $86.88,71.75,52.99$ \\
\hline$\alpha, \beta, \gamma\left({ }^{\circ}\right)$ & $90.0,100.96,90.0$ \\
\hline Resolution range $(\AA)$ & $52.03-2.00(2.04-2.00)$ \\
\hline Number of unique reflections & $21,396(1419)$ \\
\hline Completeness $(\%)$ & $97.4(92.5)$ \\
\hline Average redundancy & $3.0(3.2)$ \\
\hline$\langle I / \sigma(I)\rangle$ & $5.2(1.9)$ \\
\hline Rmeas (\%) (Diederichs and Karplus 1997) & $13.4(57.6)$ \\
\hline $\mathrm{CC}_{1 / 2}$ (Diederichs and Karplus 1997) & $98.7(87.1)$ \\
\hline Number of reflections used for the refinement & 20,186 \\
\hline Rfact $(\%)$ & 18.0 \\
\hline$R_{\text {free }}(\%)$ & 24.4 \\
\hline Bonds (Å) & 0.02 \\
\hline Angles $\left(^{\circ}\right)$ & 1.95 \\
\hline \multicolumn{2}{|l|}{ Average B-factors $\left(\AA^{2}\right)$} \\
\hline Protein & 27.9 \\
\hline Water & 30.5 \\
\hline PLP & 25.5 \\
\hline \multicolumn{2}{|l|}{ Ramachandran plot } \\
\hline Most favoured (\%) & 92.5 \\
\hline Allowed (\%) & 5.7 \\
\hline PDB entry code & 7P7X \\
\hline
\end{tabular}

\section{Conclusions}

We described the D-amino acid transaminase from bacteria H. hydrossis: the new enzyme is strictly specific towards D-amino acids and $\alpha$-keto acids and in vitro catalyzes the transamination between D-glutamate and pyruvate with one of the highest rate constants among DAATs. Furthermore, Halhy is attractive as a potential biocatalyst because of its stability at $40-50{ }^{\circ} \mathrm{C}$. We succeeded in obtaining the crystal structure of the holo form of Halhy with a resolution of $2.0 \AA$. The structural analysis revealed that the scaffold of the Halhy subunit is typical of TAs of PLP fold type IV. However, the combination of 
residues, determining the substrate specificity, is new: three arginine residues (R28*, R179, and R90) were revealed in the O-pocket. We performed molecular dynamic simulations and demonstrated that the residue R28* is responsible for D-amino acid-binding in the active site due to stable hydrogen bonds with the carboxylic group. R90 appears to assist R28* in substrate binding. We created the R179G variant of Halhy and found that the R179G mutation led to the worsening of the catalytic properties of Halhy (both $k_{c a t}$ and $K_{m}$ ); molecular dynamic simulations revealed that this is due to the decrease in the hydrogen bonds stability between the substrate and R $28^{*}$ manifested in the increased flexibility of the substrate. The observed sequence-structure-function relationships in DAATs and the members of the superfamily of TAs of PLP fold type IV in whole show the existence of various ways to achieve the desired specificity within the TA scaffold. However, changing the specificity of TAs is still a complex task in bioengineering.

Supplementary Materials: Table S1: Superposition of the Halhy subunit with the homologous TA of PLP fold type IV; Figure S2: The gel filtration elution profile for Halhy; Figure S3: The absorption spectrum of Halhy; Figure S4: pH-dependence of the Halhy spectrum in the PLP form; Figure S5: HPLC analysis of the configuration of the products of the overall transamination reaction catalyzed by Halhy; Table S2: HPLC analysis condition; Table S3: Retention times of isomers of leucine and phenylalanine after derivatization with Marfey's reagent. Figure S6: Steady-state kinetics of the transamination reactions catalyzed by Halhy; Figure S7: Steady-state kinetics of the transamination reaction catalyzed by the R179G variant. Figure S8: Omit density map for the PLP molecule in Halhy holo structure.

Author Contributions: Conceptualization, A.K.B. and E.Y.B.; Methodology, T.Y.I. and E.Y.B.; Software, M.G.K.; Validation, A.K.B., E.Y.B., K.M.B., and T.V.R.; Formal Analysis, E.Y.B.; Investigation, A.K.B., T.Y.I., K.M.B., A.Y.N., and M.G.K.; Resources, A.K.B., A.Y.N., and T.V.R.; Data Curation, E.Y.B.; Writing-Original Draft Preparation, A.K.B.; Writing—Review and Editing, A.K.B., K.M.B., M.G.K., and E.Y.B.; Visualization, K.M.B. and A.K.B.; Supervision, V.O.P.; Project Administration, E.Y.B. and M.G.K.; Funding Acquisition, V.O.P., M.G.K., and E.Y.B. All authors have read and agreed to the published version of the manuscript.

Funding: This research was funded by the Russian Science Foundation, grant number 19-14-00164 (in part of biochemical characteristics), Russian Foundation for Basic Research, grant number 18-29-13006 (in part of molecular modeling), and the Ministry of Science and Higher Education of the Russian Federation (in part of a thermal stability analysis).

Data Availability Statement: The data presented in this study are available on request from the corresponding author.

Acknowledgments: The CD measurements and MALDI-TOF MS analysis were carried out on the equipment of the Shared-Access Equipment Centre "Industrial Biotechnology" of the Federal Research Center "Fundamentals of Biotechnology", Russian Academy of Sciences. The authors acknowledge the ESRF structural biology group for the data collection. We acknowledge the use of supercomputer resources of the Joint Supercomputer Center of the Russian Academy of Sciences and the equipment of the shared research facilities of HPC computing resources at Lomonosov Moscow State University.

Conflicts of Interest: The authors declare no conflict of interest.

Sample Availability: Samples of the compounds are available from the authors. 


\section{Appendix A}

\begin{tabular}{|c|c|c|c|c|c|c|c|c|c|c|}
\hline & & R28* & & & & R90 & & & $R 179$ & \\
\hline & 21 & VSD-LSIL $\overline{L G G G I F D Y F L ~}$ & 37 & . & 85 & REAGI $\overline{\mathbf{R} L V L T G G}$ & 96 & ... 171 & -GEWIRESA $\overline{\mathbf{R} S N F F L V M ~}$ & 186 \\
\hline & 20 & VFD-HGFLYGDGVFEGIR & 36 & ... & 84 & RDAYIRPIVTRG & 95 & ... 169 & -NGYISEGSGDNIFIVK & \\
\hline $5 \mathrm{mr} 0$ & 20 & IFD-HGFLYGDGVFEGIR & 36 & 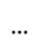 & 84 & DAYIRPIVTRG & 95 & ... 175 & -NGYVSEGSGDNIFVVK & 90 \\
\hline daa & 19 & ED-RGYQFGDGVYEVVK & 35 & ... & 83 & NTGHIYFQVTRG & 94 & ... 172 & -NNTVTEGSSSNVFGIK & 87 \\
\hline & 21 & VMS-HALHY GTSVEEGIR & 77 & ... & 89 & AYIRPLIFVG & 100 & ... 178 & -NGYISEGAGENLFEVK & 193 \\
\hline 6 nst & 25 & VLT-HTHHY $\mathbf{G M G V F E G V R ~}$ & 41 & ... & 93 & ESAYIRPMVFYG & 104 & ... 184 & -EGYVAEGSGENIFIIK & 99 \\
\hline & 25 & RGFIFGDGVYEVVP & 1 & $\ldots$ & 99 & IVY $\mathbf{Y}_{\text {IQVTRG }}$ & 09 & ... 188 & --GNVTEGSSSNVWIVK & 02 \\
\hline$r v$ & 23 & VLS-HALHYGTSVEEGIR & 40 & ... & 91 & RSCYIRPLAWMG & 120 & ... 179 & -EGYVAEGSGENLFFVR & 94 \\
\hline wh $\mathbf{x}$ & 25 & VLT-HTLHYGMGVFEGVR & 41 & 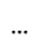 & 94 & ESCYLRPIIWIG & 105 & ... 189 & -DGYVSEGSGENEFLVN & 04 \\
\hline$h 65$ & 21 & VST-QAAFFGASLFEGVR & 37 & ... & 92 & SDVHLYVASYFG & 103 & ... 185 & VSETPGACLLMVR & 00 \\
\hline ce8 & 20 & VLS-PSLNYGFGVEEGIR & 36 & $\cdots$ & 89 & EDLYIRPVAYIS & 100 & ... 180 & -EGKVVEGSGENIFIVR & 95 \\
\hline & 21 & AAS-QATWLGSLVFDGAR & 37 & $\ldots$ & 86 & TDVYIRPMYWAE & 97 & ... 177 & VAETATSNVFMVR & 92 \\
\hline wwh & 54 & IFD-QGYLHSDVTYTVFH & 70 & & 118 & REAFVSVSITRG & 129 & ... 215 & -DGLLAEGSGFNVVVIK & 230 \\
\hline & 45 & LMD-QGFMHSDLTYDVPS & 61 & ... & & KDAFVELIVTRG & 120 & ... 206 & LTEGSGFNVLLVK & 21 \\
\hline xu3 & 44 & ILD-QGFLHSDLTYDVPA & 60 & $\ldots$ & 8 & RDAYVMMIVTRG & 119 & 204 & -DANLTEGSGFNVILIK & 219 \\
\hline xwb & 46 & MLD-EGFMRSDLTYDVPS & 62 & $\cdots$ & & RDAFVEIIVTRG & 121 & ... 206 & -DANLTEGSGFNIVLVK & 21 \\
\hline & 48 & LLD-QGFMHSDLTYDVPS & 64 & $\ldots$ & 112 & RDAFVEIIVTRG & 123 & ... 208 & -DAHLTEGSGFNIVLVK & 223 \\
\hline $6 f t e$ & 46 & LMD-QGFLHSDLTYDVPS & 62 & $\ldots$ & 110 & KDAFVEIIVTRG & 121 & ... 207 & -DGNITEGSGFNIVFIK & 222 \\
\hline & 20 & FSLFEKSLQG-AVYETLR & 36 & $\ldots$ & 84 & QEVRIKVYLFP- & 94 & 160 & -NGQVCEGSFSNVFLVK & 175 \\
\hline jxu & 28 & PTS-HAMWLGSTVFDGAR & 44 & $\cdots$ & 93 & TAIYVKRMYWGE & 104 & ... 180 & -LGNIAETGSSNIFMVK & 195 \\
\hline $6 q 1 r$ & 20 & ADD-LAAVRGDGVFETLL & 36 & $\ldots$ & 86 & DEGALRLIYSRG & 97 & ... 178 & -DGYVLEGPRSTVVIAT & 193 \\
\hline & 34 & ITD-LGITRGDGVFETIA & 50 & $\ldots$ & 103 & -ELFAKLILTRG & 113 & ... 192 & -DGYALEGPTSNVIVLA & 207 \\
\hline & 41 & EGS-TALHYGQQCEEGLK & 57 & $\ldots$ & & GSLYLRPFVIGV & 128 & ... 209 & THTTIEEAGAANEFAIT & 25 \\
\hline $6 j i f$ & 40 & EGS-TALHYGQQCFEGMK & 56 & $\ldots$ & 116 & GALYLRPFVIGV & 127 & ... 208 & THTKIEEVGSANFFGIT & 224 \\
\hline
\end{tabular}

Figure A1. The multiple structure alignment of Halhy and its close structural homologs (RMSD between C $\alpha$ 1.4-2.0 $\AA$ ) referred to by the PDB codes. The amino acid residues in the equivalent positions of R28*, R90, and R179 (numbering corresponds to Halhy) are marked in bold.

\section{References}

1. Eliot, A.C.; Kirsch, J.F. Pyridoxal phosphate enzymes: Mechanistic, structural, and evolutionary considerations. Annu. Rev. Biochem. 2004, 73, 383-415. [CrossRef]

2. Toney, M.D. Controlling reaction specificity in pyridoxal phosphate enzymes. Biochim. Biophys. Acta 2011, 1814, 1407-1418. [CrossRef] [PubMed]

3. Peisach, D.; Chipman, D.M.; Van Ophem, P.W.; Manning, J.M.; Ringe, D. Crystallographic study of steps along the reaction pathway of D-amino acid aminotransferase. Biochemistry 1998, 37, 4958-4967. [CrossRef] [PubMed]

4. Bezsudnova, E.Y.; Popov, V.O.; Boyko, K.M. Structural insight into the substrate specificity of PLP fold type IV transaminases. Appl. Microbiol. Biotechnol. 2020, 104, 2343-2357. [CrossRef] [PubMed]

5. Steffen-Munsberg, F.; Vickers, C.; Kohls, H.; Land, H.; Mallin, H.; Nobili, A.; Skalden, L.; van den Bergh, T.; Joosten, H.-J.; Berglund, P.; et al. Bioinformatic analysis of a PLP-dependent enzyme superfamily suitable for biocatalytic applications. Biotechnol. Adv. 2015, 33, 566-604. [CrossRef]

6. Höhne, M.; Schätzle, S.; Jochens, H.; Robins, K.; Bornscheuer, U.T. Rational assignment of key motifs for function guides in silico enzyme identification. Nat. Chem. Biol. 2010, 6, 807-813. [CrossRef] [PubMed]

7. Pavkov-Keller, T.; Strohmeier, G.A.; Diepold, M.; Peeters, W.; Smeets, N.; Schürmann, M.; Gruber, K.; Schwab, H.; Steiner, K. Discovery and structural characterisation of new fold type IV-transaminases exemplify the diversity of this enzyme fold. Sci. Rep. 2016, 6, 38183. [CrossRef]

8. Bezsudnova, E.Y.; Boyko, K.M.; Nikolaeva, A.Y.; Zeifman, Y.S.; Rakitina, T.V.; Suplatov, D.A.; Popov, V.O. Biochemical and structural insights into PLP fold type IV transaminase from Thermobaculum terrenum. Biochimie 2019, 158, 130-138. [CrossRef]

9. Zeifman, Y.S.; Boyko, K.M.; Nikolaeva, A.Y.; Timofeev, V.I.; Rakitina, T.V.; Popov, V.O.; Bezsudnova, E.Y. Functional characterization of PLP fold type IV transaminase with a mixed type of activity from Haliangium ochraceum. Biochim. Biophys. Acta Proteins Proteom. 2019, 1867, 575-585. [CrossRef]

10. Radkov, A.D.; Moe, L.A. Bacterial synthesis of D-amino acids. Appl. Microbiol. Biotechnol. 2014, 98, 5363-5374. [CrossRef]

11. Grishin, D.V.; Zhdanov, D.D.; Pokrovskaya, M.V.; Sokolov, N.N. D-amino acids in nature, agriculture and biomedicine. All Life 2020, 13, 11-22. [CrossRef] 
12. Yonaha, K.; Misono, H.; Yamamoto, T.; Soda, K. D-amino acid aminotransferase of Bacillus sphaericus. Enzymologic and spectrometric properties. J. Biol. Chem. 1975, 250, 6983-6989. [CrossRef]

13. Tanizawa, K.; Masus, Y.; Asano, S.; Tanaka, H.; Sodas, K. Thermostable D-amino acid aminotransferase from a thermophilic Bacillus Species. Purification, characterization, and active site sequence determination. J. Biol. Chem. 1989, 264, $2445-2449$. [CrossRef]

14. Van Ophem, P.W.; Peisach, D.; Erickson, S.D.; Soda, K.; Ringe, D.; Manning, J.M. Effects of the E177K mutation in D-amino acid transaminase. Studies on an essential coenzyme anchoring group that contributes to stereochemical fidelity. Biochemistry 1999, 38, 1323-1331. [CrossRef] [PubMed]

15. Lee, S.-G.; Hong, S.-P.; Song, J.J.; Kim, S.-J.; Kwak, M.-S.; Sung, M.-H. Functional and structural characterization of thermostable D-amino acid aminotransferases from Geobacillus spp. Appl. Environ. Microbiol. 2006, 72, 1588-1594. [CrossRef] [PubMed]

16. Kobayashi, J.; Shimizu, Y.; Mutaguchi, Y.; Doi, K.; Ohshima, T. Characterization of D-amino acid aminotransferase from Lactobacillus salivarius. J. Mol. Catal. B Enzym. 2013, 94, 15-22. [CrossRef]

17. Sugio, S.; Petsko, G.A.; Manning, J.M.; Soda, K.; Ringe, D. Crystal structure of a D-amino acid aminotransferase: How the protein controls stereoselectivity. Biochemistry 1995, 34, 9661-9669. [CrossRef] [PubMed]

18. Park, E.-S.; Dong, J.-Y.; Shin, J.-S. Biocatalytic asymmetric synthesis of unnatural amino acids through the cascade transfer of amino groups from primary amines onto keto acids. ChemCatChem 2013, 5, 3538-3542. [CrossRef]

19. Zhou, H.; Meng, L.; Yin, X.; Liu, Y.; Xu, G.; Wu, J.; Wu, M.; Yang, L. Artificial biocatalytic cascade with three enzymes in one pot for asymmetric synthesis of chiral unnatural amino acids. Eur. J. Org. Chem. 2019, 2019, 6470-6477. [CrossRef]

20. Parmeggiani, F.; Rué Casamajo, A.; Walton, C.J.W.; Galman, J.L.; Turner, N.J.; Chica, R.A. One-pot biocatalytic synthesis of substituted D-tryptophans from indoles enabled by an engineered aminotransferase. ACS Catal. 2019, 9, 3482-3486. [CrossRef]

21. Silva, M.V.D.M.; Costa, I.C.R.; de Souza, R.O.M.A.; Bornscheuer, U.T. Biocatalytic cascade reaction for the asymmetric synthesis of L- and D-homoalanine. ChemCatChem 2019, 11, 407-411. [CrossRef]

22. Walton, C.J.W.; Parmeggiani, F.; Barber, J.E.B.; McCann, J.L.; Turner, N.J.; Chica, R.A. Engineered aminotransferase for the production of D-phenylalanine derivatives using biocatalytic cascades. ChemCatChem 2018, 10, 470-474. [CrossRef]

23. Daligault, H.; Lapidus, A.; Zeytun, A.; Nolan, M.; Lucas, S.; Del Rio, T.G.; Tice, H.; Cheng, J.-F.; Tapia, R.; Han, C.; et al. Complete genome sequence of Haliscomenobacter hydrossis type strain $\left(\mathrm{O}^{\mathrm{T}}\right)$. Stand. Genom. Sci. 2011, 4, 352-360. [CrossRef]

24. Inoue, K.; Kuramitsu, S.; Aki, K.; Watanabe, Y.; Takagi, T.; Nishigai, M.; Ikai, A.; Kagamiyama, H. Branched-chain amino acid aminotransferase of Escherichia coli: Overproduction and properties. J. Biochem. 1988, 104, 777-784. [CrossRef] [PubMed]

25. Wybenga, G.G.; Crismaru, C.G.; Janssen, D.B.; Dijkstra, B.W. Structural determinants of the $\beta$-selectivity of a bacterial aminotransferase. J. Biol. Chem. 2012, 287, 28495-28502. [CrossRef]

26. Ro, H.S.; Hong, S.P.; Seo, H.J.; Yoshimura, T.; Esaki, N.; Soda, K.; Kim, H.S.; Sung, M.H. Site-directed mutagenesis of the amino acid residues in beta-strand III [Val30-Val36] of D-amino acid aminotransferase of Bacillus sp. YM-1. FEBS Lett. 1996, 398, 141-145. [CrossRef]

27. Voss, M.; Xiang, C.; Esque, J.; Nobili, A.; Menke, M.J.; André, I.; Höhne, M.; Bornscheuer, U.T. Creation of $(R)$-amine transaminase activity within an $\alpha$-amino acid transaminase scaffold. ACS Chem. Biol. 2020, 15, 416-424. [CrossRef] [PubMed]

28. Boyko, K.; Gorbacheva, M.; Rakitina, T.; Korzhenevskiy, D.; Vanyushkina, A.; Kamashev, D.; Lipkin, A.; Popov, V. Expression, purification, crystallization and preliminary X-ray crystallographic analysis of the histone-like HU protein from Spiroplasma melliferum KC3. Acta Crystallogr. Sect. F Struct. Biol. Commun. 2015, 71, 24-27. [CrossRef]

29. Pace, C.N.; Vajdos, F.; Fee, L.; Grimsley, G.; Gray, T. How to measure and predict the molar absorption coefficient of a protein. Protein Sci. 1995, 4, 2411-2423. [CrossRef] [PubMed]

30. Makarova, O.; Kamberov, E.; Margolis, B. Generation of deletion and point mutations with one primer in a single cloning step. Biotechniques 2000, 29, 970-972. [CrossRef]

31. Mikhailova, A.G.; Rakitina, T.V.; Timofeev, V.I.; Karlinsky, D.M.; Korzhenevskiy, D.A.; Agapova, Y.K.; Vlaskina, A.V.; Ovchinnikova, M.V.; Gorlenko, V.A.; Rumsh, L.D. Activity modulation of the oligopeptidase B from Serratia proteamaculans by site-directed mutagenesis of amino acid residues surrounding catalytic triad histidine. Biochimie 2017, 139, 125-136. [CrossRef] [PubMed]

32. Boyko, K.M.; Stekhanova, T.N.; Nikolaeva, A.Y.; Mardanov, A.V.; Rakitin, A.L.; Ravin, N.V.; Bezsudnova, E.Y.; Popov, V.O. First structure of archaeal branched-chain amino acid aminotransferase from Thermoproteus uzoniensis specific for L-amino acids and R-amines. Extremophiles 2016, 20, 215-225. [CrossRef] [PubMed]

33. Schätzle, S.; Höhne, M.; Redestad, E.; Robins, K.; Bornscheuer, U.T. Rapid and sensitive kinetic assay for characterization of omega-transaminases. Anal. Chem. 2009, 81, 8244-8248. [CrossRef] [PubMed]

34. Bae, H.-S.; Lee, S.-G.; Hong, S.-P.; Kwak, M.-S.; Esaki, N.; Soda, K.; Sung, M.-H. Production of aromatic D-amino acids from $\alpha$-keto acids and ammonia by coupling of four enzyme reactions. J. Mol. Catal. B Enzym. 1999, 6, 241-247. [CrossRef]

35. Beilsten-Edmands, J.; Winter, G.; Gildea, R.; Parkhurst, J.; Waterman, D.; Evans, G. Scaling diffraction data in the DIALS software package: Algorithms and new approaches for multi-crystal scaling. Acta Crystallogr. Sect. D Struct. Biol. 2020, 76, 385-399. [CrossRef] [PubMed]

36. Evans, P.R. An introduction to data reduction: Space-group determination, scaling and intensity statistics. Acta Crystallogr. Sect. D Biol. Crystallogr. 2011, 67, 282-292. [CrossRef]

37. Vagin, A.A.; Isupov, M.N. Spherically averaged phased translation function and its application to the search for molecules and fragments in electron-density maps. Acta Crystallogr. Sect. D Biol. Crystallogr. 2001, 57, 1451-1456. [CrossRef] 
38. Winn, M.D.; Ballard, C.C.; Cowtan, K.D.; Dodson, E.J.; Emsley, P.; Evans, P.R.; Keegan, R.M.; Krissinel, E.B.; Leslie, A.G.W.; McCoy, A.; et al. Overview of the CCP 4 suite and current developments. Acta Crystallogr. Sect. D Biol. Crystallogr. 2011, 67, 235-242. [CrossRef]

39. Emsley, P.; Lohkamp, B.; Scott, W.G.; Cowtan, K. Features and development of Coot. Acta Crystallogr. Sect. D Biol. Crystallogr. 2010, 66, 486-501. [CrossRef]

40. Krissinel, E.; Henrick, K. Secondary-structure matching (SSM), a new tool for fast protein structure alignment in three dimensions. Acta Crystallogr. Sect. D Biol. Crystallogr. 2004, 60, 2256-2268. [CrossRef]

41. Krissinel, E.; Henrick, K. Inference of macromolecular assemblies from crystalline state. J. Mol. Biol. 2007, 372, 774-797. [CrossRef] [PubMed]

42. Phillips, J.C.; Hardy, D.J.; Maia, J.D.C.; Stone, J.E.; Ribeiro, J.V.; Bernardi, R.C.; Buch, R.; Fiorin, G.; Hénin, J.; Jiang, W.; et al. Scalable molecular dynamics on CPU and GPU architectures with NAMD. J. Chem. Phys. 2020, 153, 044130. [CrossRef] [PubMed]

43. Best, R.B.; Zhu, X.; Shim, J.; Lopes, P.E.M.; Mittal, J.; Feig, M.; MacKerell, A.D. Optimization of the additive CHARMM all-atom protein force field targeting Improved sampling of the backbone $\phi, \psi$ and side-chain $\chi 1$ and $\chi 2$ dihedral angles. J. Chem. Theory Comput. 2012, 8, 3257-3273. [CrossRef] [PubMed]

44. Denning, E.J.; Priyakumar, U.D.; Nilsson, L.; Mackerell, A.D. Impact of 2'-hydroxyl sampling on the conformational properties of RNA: Update of the CHARMM all-atom additive force field for RNA. J. Comput. Chem. 2011, 32, 1929-1943. [CrossRef] [PubMed]

45. Jorgensen, W.L.; Chandrasekhar, J.; Madura, J.D.; Impey, R.W.; Klein, M.L. Comparison of simple potential functions for simulating liquid water. J. Chem. Phys. 1983, 79, 926-935. [CrossRef]

46. Vanommeslaeghe, K.; Hatcher, E.; Acharya, C.; Kundu, S.; Zhong, S.; Shim, J.; Darian, E.; Guvench, O.; Lopes, P.; Vorobyov, I.; et al. CHARMM general force field: A force field for drug-like molecules compatible with the CHARMM all-atom additive biological force fields. J. Comput. Chem. 2009, 31, 671-690. [CrossRef] 